\title{
COMIDA DE REFUGIADO COMO RECURSO IDENTITÁRIO E DE IDENTIFICAÇÃO
}

Célia Toledo Lucena*

Resumo: Neste artigo objetiva-se promover uma discussão teórica sobre refúgio, identidade, fronteiras étnicas, comida migratória e refletir acerca da culinária do Oriente Médio como forma de identificação e de construção/manutenção de identidades de refugiados na capital paulista. Também, iniciar discussões sobre os efeitos das diferenças culturais e as estratégias de resistência e de tradução cultural. Leva-se em conta que a cozinha e suas práticas são repletas de representações e significados e que a cultura alimentar é um marcador étnico. Os refugiados são marcados por identidades móveis, hibridismos culturais e sentimentos de pertencimento ao lugar de origem. Esse fluxo de refugiados provenientes da Síria, a partir de 2013, com a instalação de restaurantes e de venda de comida delivery, sem dúvida, estimula a ampliação dos ares multiculturais da cidade de São Paulo que é marcada por um "cosmopolitismo diaspórico".

Palavras-chave: Refugiados. Comida. Diferenças culturais. Identidade e Identificação.

\section{Refugee food as an identity and identification resource}

\begin{abstract}
This article aims to promote a theoretical discussion about refuge, identity, ethnic borders, migratory food and reflect on Middle Eastern cuisine as a way of identifying and building/maintaining refugee identities in the capital of São Paulo. And start discussions about the effects of cultural differences and the strategies of cultural resistance and translation. It is taken into account that cuisine and its practices are full of representations and meanings and that food culture is an ethnic marker. Refugees are marked by mobile identities, cultural hybridisms and feelings of belonging to their place of origin. This flow of refugees from Syria, starting in 2013, with the installation of restaurants and the sale of takeaway food, undoubtedly stimulates the expansion of the multicultural atmosphere of the city of São Paulo, which is marked by a "diasporic cosmopolitanism".
\end{abstract}

Keywords: Refugees. Food. Cultural differences. Identity and Identification

\section{Apresentação}

Este artigo propõe uma discussão sobre comida de refugiados na cidade de São Paulo. Trata-se de uma discussão teórica e de resultados exploratórios de pesquisa empírica em andamento, junto a refugiados vindos da Síria, no fluxo dos anos de 2013 a 2015. As reflexões aqui registradas revelam as primeiras respostas às indagações do projeto "A comida

\footnotetext{
* Célia Lucena, pesquisadora do CERU (Centro de Estudos Rurais e Urbanos), USP. Mediadora do GEMI (Grupo de Estudos Migrações e Identidade). Com pesquisas sobre migrantes e refugiados, diferenças culturais, fronteiras, comida étnica, identidade, memória.
} 
como cultura: hábitos alimentares e identidades de refugiados", linha de pesquisa Comida e Refugiados do GEMI (Grupo de Estudos Migrações e Identidade)1.

Nesse sentido, objetiva-se fomentar uma discussão teórica sobre refugio, identidade, fronteiras étnicas, comida migratória e refletir acerca da culinária do Oriente Médio como forma de identificação e de construção/manutenção de identidade de refugiados na capital paulista. Iniciar discussões sobre os efeitos das diferenças e as estratégias de resistência e tradução cultural ${ }^{2}$. Muitas outras questões estão sendo suscitadas, nesse estudo, tais como: as identidades nacionais estão sendo afetadas ou deslocadas pelo processo de transformação social, de globalização e da incorporação da força de trabalho migrante? Como os refugiados lidam com as fronteiras culturais ao interagirem com os diferentes? Utilizam-se de meios para determinar a pertença e a comida passa a ser o recurso cultural de sobrevivência e de manutenção de identidade étnica no país de destino? Todavia, não se pretende dar conta de responder a todas essas indagações neste texto, mas iniciar uma reflexão sobre tais questões. Nessa perspectiva, o ponto central da análise, neste artigo, é a fronteira étnica e os efeitos da diferença e o uso da comida como elemento de interação cultural e sinal de identificação e de identidade em processos de tradução.

Sendo assim, diante da hipótese de que a cultura alimentar permite reconstrução de identidades e que a comida aproxima pessoas, passa a ser usada como base de interações sociais e de inserção no país de destino. Assim, em suas residências e em restaurantes, refugiados sírios estão resignificando habilidades culinárias. A operação escolhida, além de oferecer formas para o sustento, aponta práticas de convivência a grande número de pessoas e ainda, aprendizado para transitar em um novo mundo. A comida do Oriente Médio trazida por essa leva migratória do início do sec. XXI, passa por forte aceitação na cidade de São Paulo e o facilitador para sua inserção foi a presença de alguns pratos da "culinária árabe" fazendo parte do cardápio brasileiro.

Este estudo, em andamento, sobre o uso da comida do país de origem em país de destino é de grande valia para a compreensão e percepção das soluções e estratégias usadas

\footnotetext{
1 O Grupo de Estudos Migrações e Identidade (GEMI), está ativo desde março de 2015, junto ao CERU/FFLCH/USP, com objetivos de estudar, refletir sobre diferentes modalidades das migrações contemporâneas. Entende-se por migrações contemporâneas, os deslocamentos ocorridos após a virada do século XX ao XXI. O locus dos estudos é a cidade de São Paulo, assim reflexões teóricas, estudo sobre legislações e pesquisas empíricas sobre migrantes e refugiados de diferentes etnias estão sendo realizadas, na perspectiva de linhas de pesquisa.

${ }^{2}$ Barbara Moraes Silva Pessôa e Giovanna Guimarães Casoni, graduandas de Nutrição USP, Ana Katy Lazare Gabriel, doutoranda em Educação, USP, a partir de março de 2021, fazem parte da linha de pesquisa Comida e Refugiados, do GEMI. Sou grata pela oportunidade de reflexões teóricas realizadas.
} 
pelos refugiados sírios em sua integração e aquisição de visibilidade na capital paulista. Uma vez que se leva em conta que a cozinha e suas práticas são repletas de representações e significados e que, a cultura alimentar é um marcador étnico (CONTRERAS, GRACIA, 2011) procura-se compreender quanto a comida reforça a identidade do refugiado e como constroem relações simbólicas entre as práticas alimentares e a manutenção de identidades. E perceber as operações e práticas utilizadas pelo refugiado por meios de criatividade e de imprevisto. E ainda as ações que demonstram identidades móveis, tradução cultural e o pertencimento após refugio. A comida está associada aos modos e estilos de vida do grupo, se caracterizando como uma manifestação cultural, nesse sentido, a comida faz parte de um "sistema específico e organizado de práticas, significados e valores desempenhados e estimulados" (WILLIAMS, 1992, p. 208).

Pretende-se conferir, entre os refugiados vindos da Síria, como acontece a transferência das habilidades culturais do contexto de origem ao de destino. As pessoas, uma vez, transplantadas, não desenraizadas (THOMSON, 2002), replantam a cozinha do Oriente Médio na cidade de São Paulo. Como lançam mão dos usos e táticas utilizados em país de destino e dinamizam identidades.

\section{Caminhos da investigação e das fontes}

Por meio de pesquisa qualitativa, justifica-se conhecer com mais rigor os processos das práticas e hábitos alimentares de diferentes refúgios e culturas do Oriente Médio, no contexto da cidade de São Paulo. Alguns refugiados estão sendo entrevistados em restaurantes, bares e em seus domicílios. As análises presentes neste texto, fazem parte da fase inicial da investigação, que teve início no final de 2019, todavia, a parte empírica foi interrompida em março de 2020, por conta da pandemia (COVID 19). Depois de alguns meses, em estudos teóricos, em agosto de 2021, retomou-se a pesquisa com entrevistas realizadas à distância e, a seguir, em casos especiais, retomou-se de forma presencial, por meio dos devidos protocolos para dialogar com alguns proprietários de restaurantes. Vale anunciar que a segunda fase da pesquisa em andamento, tem como foco questões sobre os hábitos e práticas alimentares, suas mudanças e transformações em país de destino.

Convém ainda, esclarecer que as entrevistas realizadas com intuito de construir uma narrativa, passam a ser um evento social que cria uma construção dialógica bivocal, momento de troca de significantes desabafos, emoções e subjetividades entre o narrador e o 
entrevistado. Diálogo significa falar entre, falar para além. Do mesmo modo, entre/vista significa olhar entre: é uma troca de olhares. O que torna a entrevista significativa é o esforço de estabelecer um diálogo entre e para além das diferenças (PORTELLI, 2010, p. 213). Utiliza-se também aqui, de matérias publicadas em jornais impressos e também em plataformas na internet. Foi de grande valia os apontamentos, de discussões realizadas nos seminários dos Grupos Migrações e Identidade e Comida e Refugiados.

Vale apresentar alguns dos refugiados, que vendem comida na capital paulista e apontar as fronteiras étnicas que carregam em sua trajetória e o refugio enquanto forma de vida. O fato de alguns serem naturais da Síria, com ascendência palestina, fez com que tais pessoas já tivessem o estigma de refugiado, mesmo antes de chegar ao Brasil. Assim, Mohammed Othman, do Restaurante Majaz, instalado na Vila Buarque, chegou em São Paulo em 2014. Tendo saído de Sbeinah (local onde nasceu), campo de refugiado palestino nas proximidades de Damasco.

Salim Mhanna, do Restaurante e Bar $B A B$ (portas abertas, em árabe), situado na Praça Roosevelt, é palestino, porém viveu por 22 anos como refugiado em Damasco, onde trabalhava com comunicação visual. Deslocou-se para São Paulo em 2015.

Bashar Alssadi, também está em São Paulo desde 2015, montou um negócio de venda delivery de esfihas, faz a produção em sua própria residência, na rua Santa Cruz. Bashar é neto de palestino, explica: "meu pai e eu nascemos na Síria, somos duas gerações de refugiados palestinos na Síria”.

Mazen Zwawe, proprietário do Restaurante Al Mazen, na Rua Mourato Coelho, já se sentia refugiado na Síria, por conta do pai ser palestino, embora a mãe seja síria. Ao contar sobre esse aspecto de sua história de vida diz: "vida inteira fui refugiado, sou palestino sírio". Mazen já trabalhava com comida em Damasco, porém ao ver seu restaurante destruído pela guerra, optou em 2013 por se transferir para São Paulo. Mantém um mural na parede do restaurante com as três bandeiras: da Palestina, da Síria e do Brasil.

Em contraponto ao grupo masculino, mencionado acima, destacam-se entre outras, duas refugiadas sírias vindas em 2014. Fátima Ismail se transferiu de Alepo, cidade industrial situada na região central da Síria, dedica-se à venda delivery de comida, que faz em casa, e ministrava aulas de pão folha, em períodos pré-pandêmicos. Antes de vir ao Brasil, Fátima havia tentado viver na Jordânia. Salsabil Matouk, também chegou em 2014, vinda de Douna, Síria. É farmacêutica, com diploma validado no Brasil, mas optou sobreviver pelos caminhos dos sabores orientais. 
O grupo entrevistado tem apontado as dificuldades da chegada, os desafios e a coragem para enfrentar as necessidades do presente. Vale salientar que a faixa de idade dos entrevistados é de 30 a 45 anos e estão distribuídos por diferentes bairros da metrópole. Uma vez instalados, as dificuldades iniciais foram as fronteiras contidas nas diferenças culturais, os primeiros passos diante das necessidades básicas no novo lugar, foi renovar o passado e inovar usos e práticas.

\section{Breve panorama do deslocamento de refugiados sírios para São Paulo}

Ao falar em refúgio cabe conceituar migração. De acordo com Sayad (1998), migração é o movimento de pessoas de um país a outro, por longo tempo ou em caráter definitivo. Distingue emigração, movimento de saída, de imigração, movimento de entrada. O emigrante e imigrante são a mesma pessoa. Autores enfocam a emigração internacional contemporânea sob a perspectiva do fenômeno considerado como um conjunto de variáveis relevantes no processo de integração global.

Muitos são os motivos, na atualidade, que estimulam os fluxos migratórios, assim, a noção da transformação social fornece base para um entendimento das ligações entre mobilidade humana e mudança social (CASTLES, 2010). Os processos ligados à acelerada globalização econômica e às reconfigurações das relações de poder político, desde o fim da Guerra Fria, representam uma mudança radical contemporânea. A transformação social, entendida como mudanças nas relações sociais, econômicas e políticas globais na sociedade contemporânea, provocam reestruturação das forças de trabalho, na fragmentação das comunidades e na redefinição das identidades (LUCENA, 2019). Daí o surgimento de outros tipos de migrantes e de modalidades migratórias.

Existem teorias distintas para diferentes categorias de migrantes, como os forçados, os voluntários, migrações familiares ou econômicas. Os motivos que levam à migração são geralmente múltiplos. Emigrantes que saem de seu país, primariamente por razões econômicas, podem também estar fugindo da opressão política. É difícil separar causas econômicas das sociais, culturais e políticas para a migração (CASTLES, MILLER, 2004). Por exemplo, por causa de desigualdade social ou opressão, certos grupos étnicos ou pertencentes a classes sociais desfavorecidas nas sociedades de origem, frequentemente têm menos oportunidades para migrar internacionalmente, o que também os desfavorece economicamente. Os indivíduos forçados a abandonar seus países são classificados como asilados, deslocados internos e refugiados. 
Os refugiados contam com proteção internacional prevista na Convenção da ONU sobre o Estatuto dos Refugiados, de 1951, no Protocolo relativo ao estatuto de refugiados, de 1967 e na Declaração de Cartagena, de 1984, sobre refugiados. O refugiado é considerado uma modalidade migratória. De acordo com a Lei Brasileira 9474/1997, é reconhecido como refugiado todo indivíduo que devido a temores de perseguição por motivos de conflitos armados, questões de raça, religião, nacionalidade, pertencimento a grupo social ou opiniões políticas e, também, devido à violação grave e generalizada de direitos humanos. A legislação brasileira reitera os princípios da Proteção Internacional dos refugiados. O refúgio é uma modalidade migratória, com várias nacionalidades de refugiados, assim, estudar modalidades permite entender as tipologias dos fluxos para compreender as migrações atuais.

De acordo com estatísticas (ACNUR, 2017) ${ }^{3}$ há cerca de 22,5 milhões de refugiados no planeta. A principal nacionalidade é a síria com aproximadamente 5,5 milhões de refugiados no mundo. Desde o começo do conflito sírio, em 2011, até o final de 2016 foram 3.772 solicitações no Brasil por sírios. A recepção de sírios foi facilitada por meio da Resolução Normativa N.17, a qual adotada em setembro de 2013 pelo CONARE (Conselho Nacional para Refugiados) e renovada em setembro de 2015, para desburocratizar a emissão de vistos, que concede por razões humanitárias, o visto apropriado. Nos últimos anos, o Brasil se afirmou como o principal país de destino, na América Latina, para refugiados sírios (LUCENA, 2020).

Segundo o Comitê Nacional para Refugiados, vinculado ao Ministério da Justiça e Segurança Pública, a capital paulista é o município brasileiro que recebeu o maior número de refugiados entre 2011 e 2019 e a nacionalidade síria é a mais presente, atrás dos venezuelanos (PINHO, 2021). Para a maioria dos entrevistados, o Brasil apresentou facilidade na obtenção de visto de refugiado, embora não ajude economicamente. Sobre isso Salim, do Restaurante e Bar BAB, diz:

Quando o refugiado chega, o primeiro documento se chama protocolo, o segundo RNE, depois o RG e, depois de uns anos, o processo de naturalização. Agora vou fazer RG, vou ficar brasileiro. E vou fazer processo de naturalização. (...) O Brasil, país lindo, povo bom e aqui não tem essa coisa de ser diferente (2020).

Por conta da guerra da Síria que já deixou mais de meio milhão de mortos, o Brasil criou normas para facilitar o visto para a população síria. Fátima, refugiada que se dedica ao comércio delivery, comenta:

\footnotetext{
${ }^{3}$ ACNUR, agencia da ONU para refugiados.
} 
O Brasil abriu as portas para gente. Fiquei quatro anos na Jordânia, antes de vir para cá. Um dia minha mãe telefonou (e contou) que caiu bomba em minha casa e roubaram o carro, eu chorei uma semana (2019).

Após receber a notícia da mãe foi ao consulado brasileiro, em Amã, na Jordânia, solicitar documentação para toda família para vir para São Paulo. "O visto custou vinte dólares por pessoa". Continua sua fala dizendo: “o avião ninguém paga pra você”. Depois de instalada conseguiu certificado de refugiada no CONARE, "mas hoje estou fazendo documento brasileiro, naturalização.” A seguir Fátima expressa seus sentimentos pelo acolhimento no Brasil, dizendo:

O Brasil tem muita gente com bom coração. Dá força para você. Na Europa ajuda pouco. Aqui o governo ajuda pouco, mas o brasileiro é gente boa (2019).

O deslocamento da população do Oriente Médio é reflexo dos conflitos gerados com a Guerra Civil Síria. A guerra civil Síria teve início em 2011, com protestos e mobilizações populares, como reflexo de outros movimentos no mundo árabe, denominados Primavera Árabe. Nos protestos em questão, a população síria exigia maior atenção aos direitos humanos, mais liberdade, mais democracia, uma nova legislação e a queda do presidente Bashar al-Assad. A disputa entre os diversos grupos levou a uma guerra civil caracterizada por grande violência e violação aos direitos humanos. O refugiado Bashar, com muita criticidade fala sobre a problemática da Síria:

A guerra não tem fim. O povo só quer ficar sofrendo e esperar Deus resolver. Não estão ligados se o governo está errado, todo mundo que está lá acredita que o governo está certo (2020).

Mohammed, conecta o fazer comida com sua região de origem: "a comida não vai resolver os problemas da guerra, mas é uma coisa que posso fazer pelo meu pais", afirma (URBANTASTE, 2019).

Mazen confirma algumas das informações acima, tanto sobre dificuldades encontradas com a guerra, como sobre a facilidade em conseguir visto, sobre isso diz:

Nasci em Damasco, sou palestino sírio. Meu pai é palestino e minha mãe síria. Nasci refugiado. Cheguei em São Paulo em 2013. O Brasil foi o país que abriu pra gente. Vim com visto de refugiado. Hoje acho que está mais difícil para conseguir visto. Não me sinto fora da Síria (...). Aqui até as ruas lembra a Síria. A cultura tem semelhança. O que é diferente é a língua e o horário de comer. Já trabalhava com comida lá. Por três a quatro anos, tive restaurante que foi destruído pela guerra (2020). 
As modalidades migratórias contemporâneas estão associadas à emergência de políticas de identidade para incluir aqueles que fazem o trajeto da emigração para a imigração e de refúgio. As identidades fragmentam-se, apoiam-se em redes sociais e se transformam em cidadãos deslocados.

\section{Refúgio, identidades, fronteiras e traduções culturais}

A marca identitária dos refugiados reflete, por um lado, a cultura e, por outro, o lugar de origem. Na sociedade atual acentua-se o novo, o fugidio, o efêmero, o fugaz, o individualismo (HARVEY, 1992). A globalização contemporânea possibilita a proliferação das diferenças, as identidades modernas estão sendo descentradas, deslocadas e fragmentadas (HALL, 2015). As reflexões de Stuart Hall (2015) sobre identidade trazem luzes para a compreensão de que as coisas estão mudando. O sujeito com uma identidade unificada e estável está se tornando fragmentado, com várias identidades, contraditórias e muitas vezes não resolvidas. Ainda o processo de identificação, por meio dos quais projetamos nossas identidades culturais, tornou-se mais provisório, variável e problemático (HALL, 2015). A cultura é a soma das práticas disponíveis, pelas quais as sociedades dão sentido e refletem suas experiências comuns. A cultura não é a soma dos costumes, mas algo que perpassa por todas as práticas sociais e constitui a soma do inter-relacionamento. Para entender determinados padrões culturais é necessário perceber como as inter-relações de todas as práticas e padrões são vividos e experimentados (WILLIAMS, 1992; HALL, 2015).

A migração causa crise na identidade, crise localizada na alteridade e no contraste entre semelhanças e diferenças (SEIXAS, 2017). Para Barth (1998) a etnicidade é uma fronteira social, a assimilação pode ocorrer, as mudanças minimizam as diferenças, logo a assimilação não requer o desaparecimento da etnicidade. A etnia, observou Stuart Hall (2015) "é o termo que utilizamos para nos referirmos às características culturais - língua, religião, costume, tradições, sentimentos de lugar - que são partilhadas por um povo" (p. 36). Dessa forma, as identidades e identificações estão sempre sendo deslocadas, diante do processo de globalização, o que possibilita pensar que a identidade cultural de refugiados é híbrida e em constante construção.

No contexto das diferentes modalidades migratórias, como já foi dito, a marca principal que os diferencia é a cultura caracterizada como uma consequência natural do lugar de origem e da geografia de nascimento. As migrações atuais e as diásporas têm ampliado a reflexão além dos limites espaciais tradicionais, mostrando os processos como as diferenças culturais se mesclam e acentuam os fatores reivindicatórios e identitários. Sendo assim, 
descarta-se aqui a ideia de entender a cultura como fenômeno puro e imóvel, mas sim como fenômeno de adaptação, criação e movimento.

As reflexões de Homi Bhabha (1998), contidas em seu livro O local da cultura, são pertinentes para iluminar as questões das diferenças, das fronteiras e o ato de tradução cultural. Assim, de forma poética, expressa sobre as questões fronteiriças da cultura:

O trabalho fronteiriço da cultura exige um encontro com o "novo" que não seja parte do continuum de passado e presente. Ele cria uma ideia do novo como ato insurgente de tradução cultural. Essa arte não apenas retoma o passado como causa social ou precedente estético; ela renova o passado, refigurando-o como um "entre-lugar" contingente, que inova e interrompe a atuação do presente. O "passado-presente" torna-se parte da necessidade, e não da nostalgia, de viver (p. 27).

Pensar em fronteira remete à variação cultural, ou seja, diferentes grupos humanos que correspondem a cada cultura. "Já que a cultura é apenas um meio para descrever o comportamento humano" (BARTH, 1998, p. 187). A diversidade entre culturas provoca fronteiras, que persistem apesar do fluxo das pessoas que as atravessam, muitas vezes acarretam processos de exclusão, de xenofobia e de discriminação. O grupo étnico compartilha valores culturais e se identifica e é identificado como tal. As fronteiras às quais chamamos atenção são fronteiras sociais. "Se um grupo conserva sua identidade quando os membros do grupo interagem com outros, isso implica critérios para determinar a pertença e meios para tornar manifestas a pertença e a exclusão" (BARTH, 1998, p.195).

Homi Bhabha (1998) encena a identidade como interação e aponta a migração como prática fronteiriça:

Mais uma vez, é o desejo de reconhecimento, "de outro lugar e de outra coisa". Mais uma vez, é o espaço da intervenção que emerge nos interstícios culturais que introduz a intervenção criativa dentro da existência. E, uma última vez, há um retorno à encenação da identidade como interação, a recriação do eu no mundo da viagem, o re-estabelecimento da comunidade fronteiriça da migração (p.29).

As diferenças se convertem em marcas identitárias (RODRIGUEZ, 2005). As dinâmicas em país de destino demonstram que as identidades contemporâneas são movediças, contraditórias, uma "celebração móvel", formada e transformada em relação às formas pelas quais somos representados e interpretados, de tal modo que as identificações estão sendo continuamente deslocadas (HALL, 2015). 


\section{A comida como marca identitária}

A alimentação, sem dúvida, é um marcador cultural de um grupo étnico, de uma nação, é resultado de representações simbólicas do cotidiano dos sujeitos. O migrante ao se defrontar com nova cultura estabelece um encontro com novos valores, novos usos e novas regras, iniciando o trabalho fronteiriço da cultura.

O momento das refeições, para as famílias árabes, são verdadeiros rituais que demonstram sociabilidade, religiosidade; a fartura e a variedade agrada a família e homenageia convidados, hábitos esses herdados dos povos mesopotâmicos. Estas práticas alimentares, a maneira à mesa, faz com que a alimentação seja escolhida como elemento cultural na busca da manutenção e de reconhecimento identitário em situação migratória.

O refugiado busca maneiras de transitar em novo mundo, instaura criatividade por meio da arte da memória, das práticas culturais e das oportunidades em país de destino. Carregam consigo os hábitos alimentares e lembranças de uma vida anterior intimamente ligada a uma vivência afetiva. Nutrem-se de imaginários, de representações, de imagens, de recordações individuais e coletivas, assim, para o refugiado a comida é memória é, também, pertença; ao recordar momentos de um passado expressa sentimentos de pertencimento e de resistência às diferenças culturais.

Os hábitos alimentares podem mudar inteiramente quando crescemos, mas a memória e o peso do primeiro aprendizado alimentar e algumas formas sociais aprendidas através dele permanecem, para sempre em nossa consciência (MINTZ, 2001, p. 32).

Dessa forma, refugiados sírios fazem uso de receitas, de técnicas, de planejamento com intuito de transferir habilidades culinárias do Oriente Médio para São Paulo. Para essa arte muito antiga de "fazer com", dá o nome de usos, trata-se de ações que revelam invenções e criações. "A culinária refere-se às maneiras de fazer o alimento transformando-o em comida" (MACIEL, 2004, p. 26). No processo de construção, afirmação e reconstrução das identidades culturais, a cozinha pode ser operada como um forte referencial, utilizado por grupos migrantes como símbolo de uma identidade própria. Os hábitos alimentares implicam formas de expressar modos e estilo de vida de determinados grupos revelando a cultura em que cada um está inserido (MINTZ, 2001; MACIEL, 2004).

Rodriguez (2005) sobre as diferenças culturais vivenciadas pela população migrante diz: 
Por sua natureza flexível e que evoca o contato e o movimento, a tanto nas sociedades "emissoras" como nas "receptoras". Não se pode perder de vista que se trata de um processo que migração está atravessada por múltiplos processos culturais que mediam sua compreensão ambienta e potencializa o encontro cultural e as zonas de contato entre grupos, em ocasiões históricas, geográficas e culturalmente diferenciados (p. 258).

$\mathrm{O}$ encontro cultural nos remete à cultura que os refugiados trazem consigo e o uso dessa cultura ao se inserir no país de chegada e a forma como negociam com as culturas locais encontradas. Salim, refugiado que se dedica ao Bar e Restaurante BAB, argumenta:

O mundo árabe é muito grande, a comida síria muito rica. A comida é a arte para mostrar sou rico, sou diferente. A história síria é a mais antiga, os outros têm influência de Damasco. A qualidade da comida síria tem qualidade muito alta (2020).

Fátima, ao explicar o porque da comida de origem como forma de sobrevivência, demonstra significados das práticas alimentares na cultura árabe. Lembra:

Quando alguém entra na sua casa, a primeira coisa que põe na mesa é o pão. Amigo compartilha da minha casa, da minha mesa. Se dei pão a ele não vai me fazer mal. Compartilhar com a gente comida, não pode fazer coisa ruim (...). A comida é servida sempre, quando nasce o bebe, serve café, comida. $\mathrm{E}$ quando morre, também serve café e muita comida (2019).

Simmel (2004) lembra que o comer e beber juntos, para o árabe permite transformar um amigo mortal desconhecido em amigo, dessa forma, o comer e beber juntos libera uma enorme força socializadora, baseada em ideia primitiva de que se produz deste modo carne e sangue comuns.

Mazen conta sobre a fartura da mesa árabe e dos horários das refeições:

Eles não conseguem ficar com um prato só. Depende do momento, se for à noite as mulheres fazem a comida e os homens ficam tomando chá. Depois da comida vem a sobremesa. O café da manhã é por volta de $9 / 10$ horas. $O$ almoço às $15 \mathrm{~h}$ e o jantar às $9 \mathrm{~h}$. O café da manhã é falafel, chá e comidas (2020).

As operações vividas por migrantes se multiplicam com a extensão dos fenômenos de assimilação ou aculturação (TRUZZI, 2012), ou seja, os deslocamentos substituem maneiras de transitar pela identificação com o lugar. Essas pessoas são obrigadas a negociar com as novas culturas em que vivem, sem simplesmente serem assimiladas por elas e sem perder suas identidades, carregando os traços culturais, as linguagens e as marcas particulares. Assim, propõe-se pensar que a identidade cultural de refugiados é híbrida e em constante construção.

As pessoas pertencentes às culturas híbridas renunciam à pureza cultural perdida. Salim aponta algumas negociações que faz ao pensar sua comida, tendo em vista não alterar o conteúdo das receitas, mas atender o paladar do brasileiro. Sobre isso diz "a comida árabe do 
Brasil, infelizmente, não tem sabor certo, é muito ruim, uma coisa totalmente diferente, tudo errado", se referindo à comida árabe que encontrou em São Paulo, no momento de sua chegada. Pretende inovar e criar um novo cardápio árabe e que atenda ao paladar brasileiro. Salim explica:

Eu escolhi comidas que não existe no Brasil. Fiz pesquisa sobre o que o brasileiro gosta. Uma comida árabe com adaptação o brasileiro gosta. $\mathrm{O}$ brasileiro gosta de arroz, carne e salada. Escolhi vários pratos que é mais próximo disso. Nossa culinária tem várias opções de arroz, como o arroz com lentilha, com cebola caramelizada. Estou fazendo fábrica de comida vegana e vegetariana, mas em comida árabe (...) temos que fazer adaptação em duas coisas. O tempero nosso é muito forte. Temos que fazer adaptação do tempero, ficar menos forte, outra coisa são os ingredientes, muitas nozes, frutas secas, fica muito caro (2020).

Mazen também tem uma proposta de manter a particularidade das receitas no país de destino, assim, diz:

Se você quer mostrar para o brasileiro o que é comida árabe, é uma coisa. Agora se você só quer trabalhar com comida, só para ganhar dinheiro, não tem futuro. Eu faço a comida do jeito que a gente come lá (Síria). Tudo a mesma coisa. Tem temperos que tem aqui, outros eu preparo. Você deve ficar naquilo que você conhece. Tem que seguir naquilo que acredita. Minha comida sempre foi minha vida. É uma coisa que eu amo. Há 15 anos eu trabalho com comida, fiz curso e trabalhava em restaurantes para aprender (2020).

Já Bashar, nasceu na Síria, onde viveu por muitos anos, durante a guerra esteve no Líbano e Egito. Pediu o visto para vir para São Paulo no consulado brasileiro no Egito. Manteve sempre a condição de refúgio por ser neto de palestino. Assim que chegou fez negociações robustas com a cultura do país de acolhida. Logo que chegou se casou com uma brasileira e encontrou ajuda para apreender o idioma e dicas que facilitaram hibridismos culturais e assimilações. Sobre suas adaptações culturais diz:

Logo que cheguei comecei a comer carne de porco. A primeira coisa foi desacreditar no Deus. Para a gente a carne de porco não existe. No começo fiquei pensando que estava comendo um bicho nojento, que não se pode comer. Mas agora já não penso mais isso (2020).

Depois de algumas tentativas de trabalho não muito bem-sucedidas, Bashar resolveu montar seu próprio negócio. Fez contato por rede social, com a irmã que vive no Egito e pediu a receita de esfiha e em 2018 montou seu empreendimento em sua própria casa. Hoje se sente cozinheiro, com um trabalho encaminhado e diz: "pelo menos tenho um país". Bashar, sem preocupação em manter fortes sentimentos de pertencimento ao país que nasceu, descreve as traduções e hibridismos que sofreram as esfihas: 
Muita coisa tirei da receita, porque não se acha aqui. Adaptei aqui para vender mesmo. Faço recheios de ricota e de muitos sabores. E também uma linha de esfiha doce, com damasco, chocolate, banana e outros (2020).

Bashar faz aproximações com a cultura do lugar de destino buscando sucesso no trabalho como forma de inserção. Por sua vez, as diferenças culturais se minimizam e as fronteiras se tornam menos nítidas.

Fátima, leva em conta não só o paladar, mas as trocas e dádivas: "aqui todo mundo gosta da comida árabe”. O que a fez optar pela comida foi a facilidade em exercitar uma atividade profissional, com pouco conhecimento do idioma local. Nos primeiros momentos "trabalhei só de graça, convidava amigos e levava pros amigos, pro médico, é porque ele me ajuda bastante, eu não pago dinheiro pra ele nada". Para responder à pergunta sobre os significados em fazer comida de sua região de origem, em país de destino, Fátima de forma emocionada, explica:

Significa muita coisa para mim (choro). Muito maior, não só para ganhar dinheiro. Primeiro, tá ganhando a pessoa como parente (...) Porque eu tá precisando de amigos, preciso pessoa, preciso parente. Tem pessoa brasileira que deixa eu sentir essa parte, não é só por dinheiro (2020).

As identidades são irrevogavelmente traduzidas (HALL, 2015). A palavra tradução, observa Salman Rushdie (1991): "vem, etimologicamente, do latim, significando transferir; transportar entre fronteiras”. Assim, as pessoas que pertencem a dois mundos ao mesmo tempo, são pessoas deslocadas, deixando para trás uma vida passada e transplantadas em outro mundo, não sendo, dessa forma, desenraizadas (THOMSON, 2002; HALL, 2015). Os migrantes são transplantados para uma realidade que oferece novas experiências, todavia preservam traços identitários de seu passado porque trazem em suas malas práticas culturais vividas no lugar de origem.

Fátima, comenta que ao chegar "já tinha duas culturas, a síria e a curda”. A comida é similar, "mas às vezes misturo e faço prato curdo também". O gosto da refugiada vai sendo traduzido, embora procure manter a originalidade das receitas, encontra dificuldade em encontrar alguns condimentos, como "por exemplo, o sumac ${ }^{4}$ daqui é fraca, não igual do nosso lá, é caro". Para ela o condimento chave é o zatar, que ela mesmo prepara. Vai se traduzindo diante da fronteira da culinária do novo país, diante do arroz e feijão, a comida cotidiana do brasileiro, faz uma inovação com hibridização, ao temperar o feijão com seus condimentos de origem, como forma de reconciliar a comida síria com a brasileira. Sendo

\footnotetext{
${ }^{4}$ Sumac, tempero de sabor azedo, usado em saladas, Kebabi e carnes grelhadas.
} 
assim, coloca azeite de oliva, tahine, salsinha e romã. E a seguir degusta com pão. Segundo Fátima, a inventiva atendeu ao paladar das crianças.

É, meu filho ama, ele fala: cadê esse tahine com feijão. A gente ama. Muito delicioso, maravilhoso. A gente come com pão. O youtube é melhor escola, já aprendi coxinha (2020).

A mistura entre diferentes culturas não enfraquece nem destrói sua própria cultura. Assim, Fátima reforça caminhos de interação, ao ministrar aulas do pão folha, tece narrativas aos alunos, traçando comparações entre a cultura do passado e a do presente. Sobre determinados alimentos diz: "lá pobre come mijadra, aqui rico come mijadra. Lá rico come banana, aqui pobre come banana”. Mostra algumas diferenças sociais, econômicas e na produção de alimentos e nas técnicas do fazer comida entre árabes e brasileiros. A maneira de fazer café, segundo a refugiada, apresenta diferenças, ao explicar, fornece a receita do "café turco": "põe água e o pó de café na panela, deixa ferver com cardamomo, depois despeja e deixa o pó no fundo". Ao contar que é de ascendência curda explica que as diferenças regionais da comida árabe são mínimas. "os curdos usam muito azeite, preparam azeite este ano e usam o ano que vem".

No que se refere à problemática das identidades, das identificações, na afirmação, construção, reconstrução e reconhecimento, a cozinha é operada como recurso e utilizada como algo simbólico de um determinado grupo migrante ou em refugio. A identificação nunca é afirmação de uma identidade pré-estabelecida, "é sempre a produção de uma imagem de identidade e a transformação do sujeito ao assumir aquela imagem" (BHABHA, 1998, p. 76).

Salim, bastante confiante em suas experiências, já se identifica como comerciante:

Cheguei cinco anos atrás, como refugiado, hoje sou comerciante e vou ficar fabricante (...) A comida me atrai, a comida é como música, te atrai, o árabe é inteligente em adaptar comida. Com a comida pode mostrar sua cultura e se relacionar com mais gente (2020).

As atividades culinárias constituem, para a maioria dos refugiados, um trabalho, mas podem ser também atividade prazerosa e criativa, constituindo uma arte que exige memória e imaginação. Passa a ser uma forma de se relacionar social e culturalmente.

\section{Refugiados sírios inovam a culinária "árabe” na cidade de São Paulo}

A primeira leva de migração árabe para o Brasil aconteceu por volta do ano de 1880 . Com a crise do império otomano, a segunda leva, considerada um grande fluxo foi a partir de 1950, após a segunda guerra. A presença de comida árabe introduzida pela leva migratória 
dos anos de 1950, se propagou por meio de restaurantes, de comidas de bares e também no cardápio cotidiano de famílias paulistas. A leva pós-guerra transplantou o cardápio da época, principalmente do Líbano, dando origem aos restaurantes árabes paulistas inaugurados nos anos entre 1945 e $1955 .{ }^{5}$ Essa prática culinária já arraigada facilitou o recomeçar a vida da terceira onda de migração vinda do Oriente Médio, a partir de 2011, em decorrência da guerra civil na Síria. Não tiveram que educar o paladar do paulistano, tampouco grandes dificuldades em encontrar os condimentos, assim, estão contribuindo para a ampliação de ares multiculturais na capital paulista.

Alguns refugiados sírios, na última década, vêm criando em São Paulo um nicho étnico, com visibilidade ao exibir as habilidades culinárias migradas do Oriente Médio. A cozinha é um espaço para muitos dos refugiados sírios, que tinham outra profissão, eram engenheiros, artistas, mas o empreendimento se tornou uma forma de sobreviver em São Paulo. Os cardápios saem de cozinhas do Oriente Médio, apesar de terem muita semelhança, se identificam com o rótulo de "comida síria ou árabe". Conheciam pouco sobre a realidade do país de acolhida, nem sabiam falar a língua, mas, uma coisa que contribuiu para sua inserção, foi encontrar a comida árabe no cardápio do dia-a-dia dos brasileiros.

Os imigrantes que vieram para São Paulo, nos anos 1940/1950, instalaram os primeiros restaurantes, todavia, nem todos tinham Síria como país de origem, muitos eram oriundos do Líbano, trouxeram na bagagem a culinária similar existente na região (PINHO, 2021). O cardápio que está sendo introduzido pelos refugiados chegados a partir de 2013, traz novos sabores e novas opções da cozinha do Oriente Médio. Até então, os pratos mais degustados em restaurantes eram o quibe, esfiha, kafta, charutos e tabule, porém, agora está sendo oferecido com mais frequencia falafel, eajah ${ }^{6}$, fattaha ${ }^{7}$, sanduiches como o shawarma (carne) e o shish taouk (frango) dentro de inúmeras outras novidades, em pequenos restaurantes dando outros ares à capital paulista.

Os novos chefs afirmam que os pratos introduzidos diferem dos receituários já existentes, abrasileirados, tanto em opções como nos condimentos e modos de preparo. Ainda que os pratos mais conhecidos são os mais procurados. Salsabil comenta que seu babaganuche difere das pastas de berinjela encontradas nos cardápios de restaurantes árabes

\footnotetext{
${ }^{5}$ Os primeiros restaurantes árabes inaugurados em São Paulo, foram: a Brasserie e Rotisserie Victoria (1947), o Almanara (1950), o Bambi (1951) e o Jaber (1952).

${ }^{6}$ Eajah é como um tempurá sírio vegetariano, frito na chapa e vendido como lanche, feito com batata, farinha de trigo, ovos, cebola e hortelã.

${ }^{7}$ Fattaha é um prato que intercala camadas de pão torrado, arroz e frango com castanhas.
} 
brasileiros, assim, compara além da pasta de berinjela com tahine (gergelim), “o original da minha terra leva tomate, cebola, nozes e romã” (PINHO, 2021, B13).

Salsabil acrescenta:

A comida síria de São Paulo virou um pouco brasileira, mas as famílias de origem árabe gostam de pedir as receitas originais de lá, como nossos avós faziam (PINHO, 2021, B13).

Mohammed, investe em seu empreendimento, capricha na seleção dos pratos, mantém uma equipe de refugiados do Oriente Médio na cozinha e diz:

Você entra aqui [no Majaz] e come como em qualquer outro restaurante. Fazemos comidas caseiras todos os dias, que merecem ser pagas por preço justo (URBANTASTE, 2019).

Dessa maneira, sem tirar a originalidade do prato, fazem adaptações para agradar os comensais brasileiros, tais como a redução e troca de condimentos, a adoção da carne bovina no lugar do carneiro, a diminuição de frutas secas. Fátima, quando solicitada, produz shish barak, um prato sírio-libanes, com pequenos bolinhos de massa recheados de carne, cozidos em um ensopado de iogurte natural. Sobre os ajustes dos condimentos Fátima diz:

Quando em festa, faz shish barak, eu levo meu material. Eu falo coloca cominho com alho frito. Porque tem muita gente que não gosta de alho frito com cominho, a gente faz do jeito que a pessoa vai comer. Mas se a pessoa não, não gosta, não coloca nada. Mas muita gente deixa igual, faço do meu jeito(2020).

Com o apoio da ONG Migraflix, do programa Airbnb Experiences e da divulgação da mídia que valoriza a comida do refugiado árabe em detrimento de outros grupos étnicos, que chegam a ser menosprezados, vão ganhando espaço com vendas no mercado delivery e em restaurantes recém instalados em diferentes bairros na metrópole paulistana. Comentam que durante a pandemia do COVID 19 perderam movimento, clientes, trabalhos. A quarentena provocou um retrocesso nos serviços e nos projetos pessoais, principalmente para os que arriscam trabalhar com restaurantes, mais do que para os serviços delivery. Todos mantêm uma esperança de em breve reconquistar sucessos econômicos por meio dos caminhos dos sabores. 
A sociedade global na condição pós-moderna (HARVEY, 1992; HALL, 2015) leva a múltiplas identidades e pertencimentos, gera sociedades multiculturais e identidades movediças. Assim, a sociedade multicultural supõe justaposição de etnias e diversidade de culturas. São Paulo, sem dúvida, é uma cidade multicultural com a presença de membros de diferentes grupos étnicos. A cidade é marcada por um "cosmopolitismo diaspórico", com novas dinâmicas a partir das outras levas que chegam desde 2010. Existe um trânsito de sírios, palestinos, africanos, haitianos, bolivianos e outros, em redes de apoio, em ocupações habitacionais, em cursos de português, em feiras e comércio de rua. São Paulo é um polo de rotatividade migratória na América Latina. E a cidade vista como um composto de redes e tramas, nos dias atuais, permite visualizar a inserção de alguns grupos e a forma como redesenham o espaço urbano.

\section{Considerações finais}

Mesmo diante de uma pesquisa exploratória, permite deixar aqui algumas conclusões sobre o uso da comida síria como operação escolhida, além de oferecer formas para o sustento, aponta práticas de convivência com um número grande de pessoas e ainda, aprendizado para transitar e viver em um novo mundo. O migrante, "sem sair do lugar onde tem que viver e que lhe impõe uma lei, ele aí instaura pluralidade e criatividade e lida com imprevistos" (CERTEAU, 1994, p. 93).

Para Bourdieu (1979), o que diz respeito à comida são objetos que não sofrem influência no modelo escolar. Sendo assim, continua na trajetória de vida a mais estreita relação com o habitus recebido na origem. Em suas próprias residências e em restaurantes, os refugiados sírios estão desenvolvendo inventabilidades e resignificando habilidades. Barth (1998) lembra:

(...) a persistência de grupos étnicos em contato implica não apenas critérios e sinais de identificação, mas igualmente uma estruturação da interação que permite a persistência das diferenças culturais (p. 196).

Todavia, esses "entre-lugares" fornecem o terreno para elaboração de estratégias de subjetividade que dão início a novos signos de identidade e espaços inovadores de convívio. $\mathrm{O}$ ato de definição da proposta de um novo mundo, marcado com intercâmbio de valores e de diálogos (BHABHA, 1998).

Os refugiados sírios, uma vez transplantados para São Paulo, iniciam um processo de tradução cultural, utilizam de maneiras de fazer, de artes de criar e de inventar, 
compartilhando elementos culturais que lhes proporcionam sentimentos de pertencimento ao local de origem e, ao mesmo tempo, buscam visibilidade e reconhecimento. Tornou-se possível a compreensão da manutenção de fronteiras, no convívio social entre pessoas de culturas diferentes, ainda que os limites culturais persistam. Todavia, os contrastes promovidos pela comida étnica permitem a persistência das diferenças e se torna um relevante caminho para interação, aproximação e identificação com pessoas por meio da cultura do lugar de origem em país de refúgio.

\section{Entrevistados}

Salim Mhanna, entrevista concedida em 3-02-2020. No BAB, Bar e Restaurante, Praça Roosevelt, São Paulo.

Fátima Ismail, entrevistas concedidas em 15-11-2019 e 06-03-2020. Em sua residência, na Vila Gumercindo, São Paulo.

Bashar Alssadi. Entrevista concedida em 2-03-2020. Em sua residência. Vila Mariana. São Paulo.

Mazen Zwawe. Entrevista concedida em 17-02-2020. Em seu Restaurante Al Mazen. Rua Mourato Coelho, São Paulo.

\section{Referências Bibliográficas}

ACNUR. Statistical online database. Brasília (DF), 2017. Disponível em: http:www.unhcr.org BHABHA, H. O local da cultura. Belo Horizonte: UFMG, 1998.

BARTH, F. Grupos étnicos e suas fronteiras. In: POUTIGNAT, P.; STREIF-FENART, J. Teorias da etnicidade. São Paulo: UNESP, 1998.

BOURDIEU, P. La distincion critique sociale du jugement. Paris: Minuit, 1979.

CASTLES, S. Contextualização: entendendo a migração global: uma perspectiva desde a transformação social. Rev. Inter. Mob. Humana, Brasília, Ano XVIII, n. 35, p. 11-43, jul./dez., 2010.

CASTLES, S.; MILLER, M. La era de la migracion. Mexico: Universitad Autonoma de Zacatecas, SEGO, INM: Colosio, 2004.

CERTEAU, M. A invenção do cotidiano: artes de fazer. Petrópolis: Vozes, 1994.

CONTRERAS, J.; GRACIA, M. Alimentação, sociedade e cultura. Rio de Janeiro: Fiocruz, 2011.

HALL, S. A identidade cultural na pós-modernidade. Rio de Janeiro: Lamparina, 2015.

HARVEY, D. A condição pós-moderna. São Paulo: Loyola, 1992.

LEI 9474/97: Estatuto Nacional do Refugiado. Presidência da República, Casa Civil, 22 de julho de 1997.

LUCENA, C. Ensinar para aprender a viver em um novo mundo. Cadernos CERU, São Paulo, v. 31, n. 1, p. 268-280, 2020.

Migrações contemporâneas e impasses identitários: algumas teorias e conceitos.

Cadernos CERU, São Paulo, v. 30, n. 1, p. 19-49, jun. 2019. 
MACIEL, M. E. Uma cozinha à brasileira. Estudos Históricos, Rio de Janeiro, n. 33, p. 25-39, 2004.

MINTZ, S. Comida e Antropologia: uma breve revisão. Revista Brasileira de Ciências Sociais, v. 16, n. 47, 2001.

PINHO, F. Novos refugiados sírios trazem facetas inéditas da culinária árabe. Folha de $S$. Paulo, São Paulo, 9 mar. 2021. Caderno Comida, B 13.

PORTELLI, A. Ensaios de História Oral. São Paulo: Letra e Voz, 2010.

RODRIGUEZ, M. L. Cultura y migración: los procesos de naturalización de la diferencia. Migración, Desplazamiento forzado y Refugio. Quito: Programa Andino de Derechos Humanos y Democracia. UASB-PADH/UNION EUROPEIA/GRUPO SOCIAL FEPP/PLAN MIGRATIÓN, 2005.

RUSHDIE, S. Imaginary homelands. London: Granta Books, 1991.

SAYAD, A. A imigração ou os paradoxos da alteridade. São Paulo: USP, 1998.

SEIXAS, R. Migração simbólica e dialética da identidade cultural nos processos de migração. Brazilian Journal of Latin American Studies, v. 15, n. 29, p. 14-37, 2017. Disponível em: https://doi.org/10.11606/issn.1676-6288.prolam.2016.128802

SIMMEL, G. Sociologia da refeição. Estudos Históricos, Rio de Janeiro, n. 33, p.154-166, 2004.

THOMSON, A. Histórias (co)movedoras: história oral e estudos de migração. Revista Brasileira de História, São Paulo, v. 22, n. 44, p. 341-364, 2002.

TRUZZI, O. Assimilação re-significada: novas interpretações de um velho conceito. Dados Revista de Ciências Sociais, Rio de Janeiro, v. 55, n. 2, p. 517-553, 2012.

URBANTASTE. Disponível em www.uol.com.br/urbantaste/noticias redação/2019/08/27/conheça-7-restaurantes-comandados-por-refugiados-em-sao-paulo.htm.

Acesso em: 14 jun. 2021.

WILLIAMS, R. Cultura. São Paulo: Paz e Terra, 1992. 